\title{
Calculation of electrochemical parameters starting from the polarization curves of ferrocene at glassy carbon electrode
}

\author{
N. S. Neghmouche, T. Lanez* \\ VTRS Laboratory, Institute of Sciences and Technology, University of El-Oued, B.P.789, 39000, \\ El-Oued, Algeria
}

*E-mail address: nasersaleh78@yahoo.fr

\section{ABSTRACT}

This work is a contribution to the calculation of electro aemcal from the polarization curves of ferrocene. The parameters are: The anodic and the dic $\left(E_{\mathrm{pc}}\right)$ peak potentials, as well as the corresponding anodic $\left(i_{\mathrm{pa}}\right)$ and cathodi $\left(i_{\mathrm{pc}}\right)$ currents were obtained at different scan rates $\left(0.05,0.10,0.30,0.50{\mathrm{~V} . \mathrm{s}^{-1}}^{-1}\right.$. The half-wa investigated solvents have been evaluated. The diffusion oefficients $(D) h_{\mathfrak{a}}$ been calculated using
the Randles-Sevcik equation.

Keywords: Cyclic voltammetry; diffusion coefficient; fe one; half wave potential; Randles-Sevcik equation

\section{INTRODUCTION}

Many studies and ys vercurochemical methods were effected on the oxidoreducing properties of $f$ ocene. In eral, the cathodic behavior ferrocene usual in organic media such as dich rom ane, acet nitrile and DMF can be described by a reversible reduction in an el tron, leac to ion Ferrocerium [1]. In the present work the oxidation of ferrocene, $\mathrm{Fe}\left(\mathrm{C}_{5} \mathrm{H}_{5}\right)_{2}$ to the fo cenium cation, $\mathrm{Fe}\left(\mathrm{C}_{5} \mathrm{H}_{5}\right)_{2}{ }^{+}$, was examined in the solvents dichloromet ${ }^{1}$ so .... nn containing tetrabutylammonium tetrafluoroborate, and aqueous solution contan sulfuri acid using the technique of cyclic voltammetry [2,3]. The results indicat at rea reartons of ferrocene/ ferricenium couple were a reversible process of diff sion-c htrolled, gle electron transfer in both studied solutions.

$\mathrm{T}^{\mathrm{T}}$ was conducted on a fixed electrode of glassy carbon with different scanni. peeds $\left(0.05,0.10,0.30,0.50 \mathrm{Vs}^{-1}\right)$ and we had a study on rotating electrode with different Hon speeds (400.600.800.1000 rpm), and we calculate some electrochemical parameters starting from the polarization curves of ferrocene. The parameters are: The anodic $\left(\mathrm{E}_{\mathrm{pa}}\right)$ and the cathodic $\left(\mathrm{E}_{\mathrm{pc}}\right)$ peak potentials, as well as the corresponding anodic $\left(\mathrm{i}_{\mathrm{pa}}\right)$ and cathodic $\left(i_{p c}\right)$ peak currents, and the half-wave potentials $\left(E_{1 / 2}\right)$ were obtained at different scan rates and different rotation speeds.

The diffusion coefficients (D) have been calculated using the Randles-Sevcik equation [4]. Electrochemical study of organic compounds and in particular cyclic voltammetry is an efficient and convenient approach for the in situ characterization of mass transfer of probe molecules; it has been used to evaluate the diffusion of redox-active reagents in many systems 
[5]. In addition, because the redox reaction of ferrocene/ferricenium $\mathrm{Fe}\left(\mathrm{C}_{5} \mathrm{H}_{5}\right)_{2} / \mathrm{Fe}\left(\mathrm{C}_{5} \mathrm{H}_{5}\right)_{2}^{+}$ couple is reversible and Nernstian in the majority of organic solutions and its redox potential is little influenced by such solvents, $\mathrm{Fe}\left(\mathrm{C}_{5} \mathrm{H}_{5}\right)_{2}$ is usually chosen as redox probe for nonaqueous system [6].

\section{ELECTROCHEMICAL PROPRIETIES}

It is well known that ferrocene easily undergoes one electron oxidation to form ferricenium cation $\mathrm{Fe}\left(\mathrm{C}_{5} \mathrm{H}_{5}\right)_{2}^{+}$in a reversible manner [7] figure (1). Thus, we investigated the ferrocene electrochemical behaviors in organic and aqueous mediums.

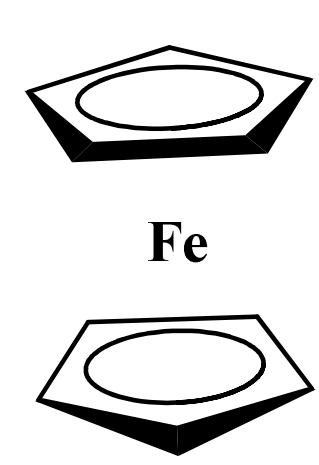

Fig.1 Reversible mono

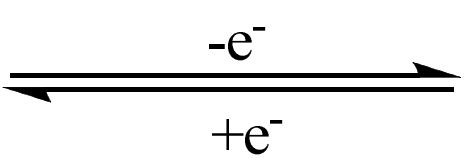

In previous work [2] we morted e electrochemical behavior of $\mathrm{Fe}\left(\mathrm{C}_{5} \mathrm{H}_{5}\right)_{2}$ / $\mathrm{Fe}\left(\mathrm{C}_{5} \mathrm{H}_{5}\right)_{2}^{+}$couple on a platiny $1(\mathrm{Pu}$ lectrod In present work, we report electrochemical behavior of ferrocene in dich net me and in aqueous ethanol. Electrochemical behavior of ferrocene and ferriceniy ar oup n bour solutions was investigated by cyclic voltammetry using conventional clas arbon ele do.

\section{EXPERIMUNTAL}

\section{1. Matena}

aronic oxion or ferrocene.

All xpern thts wer arried out in dichloromethane or in aqueous ethanol. $10^{-1} \wedge$ three electrode configuration was used. The working electrode was a glassy carbon(dh ter $2 \mathrm{~mm}$ ) electrode. the reference electrode was a saturated calomel electrode (SCE). The counter electrode was a platinum wire. Potentials were calibrated against ferrocene. The experiments were carried out under a moisture free argon atmosphere. Cyclic voltammetry was measured for a dichloromethane and aqueous ethanol solutions of ferrocene $\left(10^{-3} \mathrm{M}\right)$.

\section{2. Chemicals}

Ferrocene (Fluka, 98\% purity) and sulfuric acid (Fluka, 99\% purity ) were used as received, the electrolyte salt tetrabutylammonium tetrafluoroborate $\mathrm{Bu}_{4} \mathrm{NBF}_{4}$ (Fluka, 
electrochemical grade $99 \%$ purity) was dried for $1 \mathrm{~h}$ at $105{ }^{\circ} \mathrm{C}$ before use. Dichloromethane (Sigma-Aldrich, 99.9\% purity) was dried over molecular sieves before use. Argon plunging tube bottle was provided by Linde (Linde gas algérie). All the freshly prepared solutions were degassed under argon gas flow before experiments.

\section{RESULTS AND DISCUSSION}

\section{1. Electrochemical measurement on a fixed electrode}

Cyclic voltammograms of ferrocene at glassy carbon electrode were performed at concentration of $10^{-3} \mathrm{M}$ of ferrocene in deoxygenated dichloromethane and in aqueous ethanol solutions with respectively $10^{-1} \mathrm{M}$ of $\mathrm{Bu}_{4} \mathrm{NBF}_{4}$ and $\mathrm{H}_{2} \mathrm{SO}_{4}$ as supporting crec. each solution was scanned at scan rate equal to $0.05,0.10,0.30$ and $0.50 \mathrm{~V} . \mathrm{s}^{-1}$ The result $\mathrm{CV}$ curves and the electrochemical parameters are shown respectively in figure $\mathrm{d}$ table

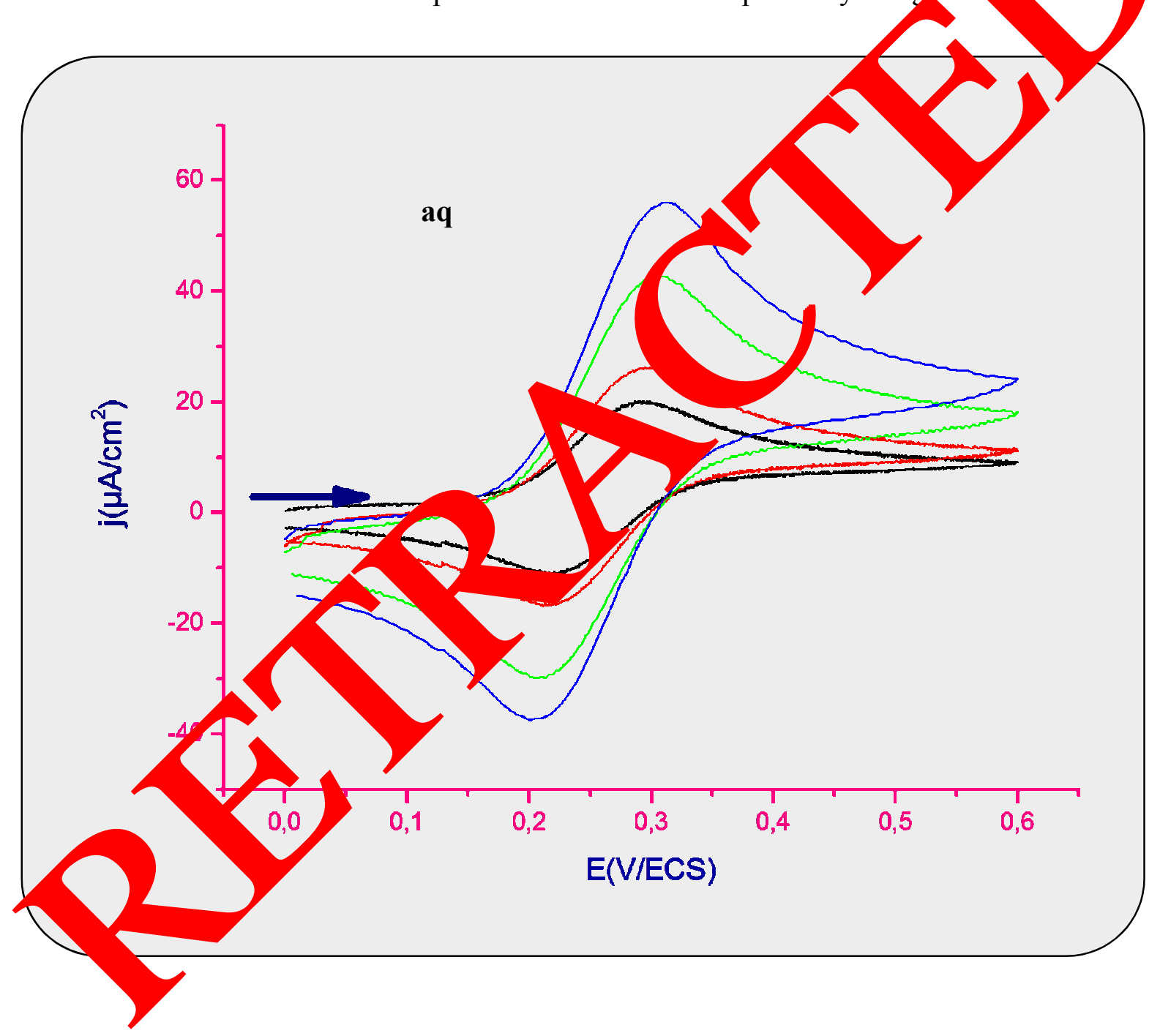

(A) 


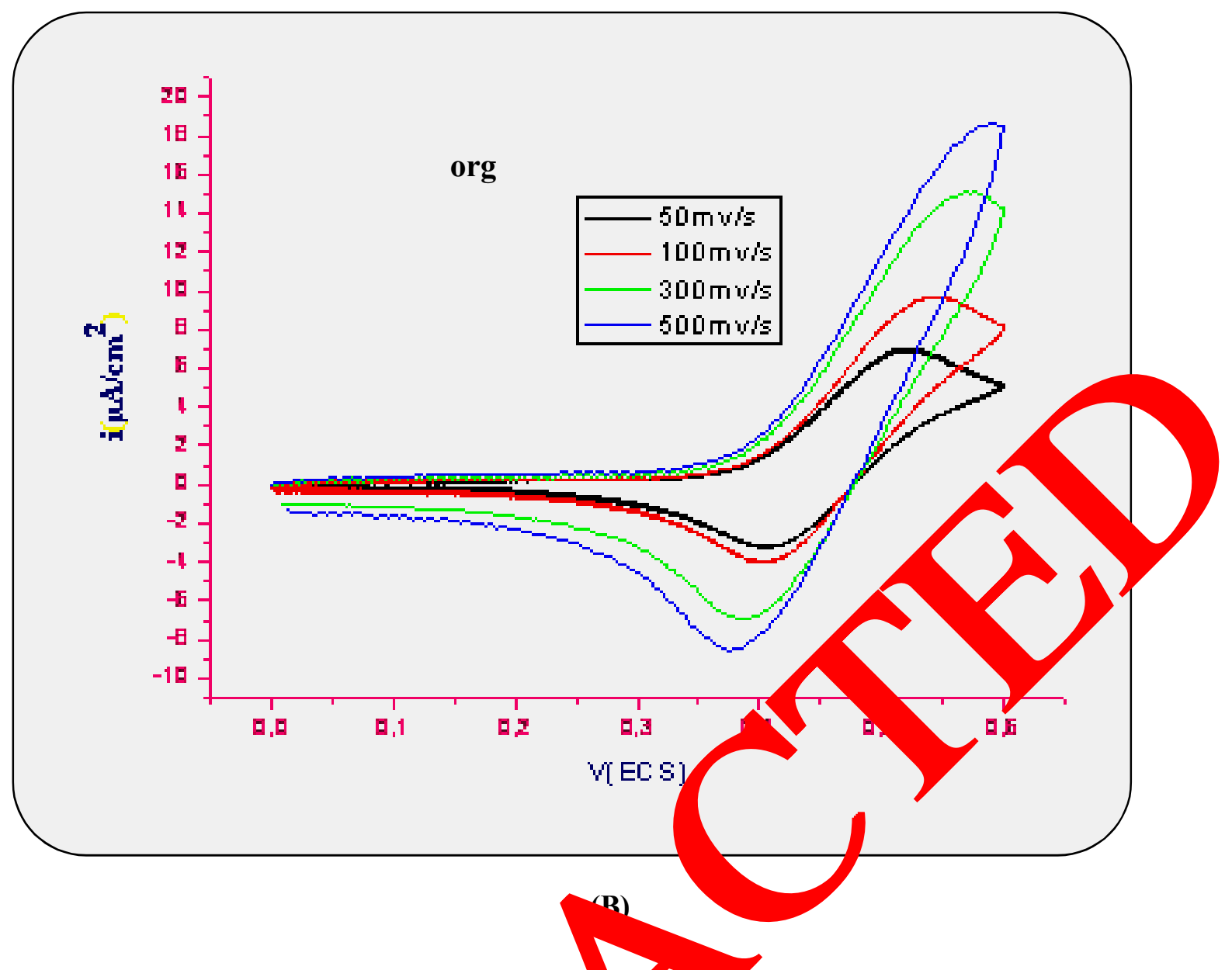

Fig. 2 ( A, B). cyclic voltammetry of ferrocene 1 and, $00 \mathrm{mM} \mathrm{Bu} \mathrm{NBF}_{4}$ in $\mathrm{CH}_{2} \mathrm{Cl}_{2}$ (left) and 1 $\mathrm{mM}$ of ferrocene in ethanol/aq. $\mathrm{H}_{2} \mathrm{SO}$ t) at $2 \mathrm{~m}$ diameter glassy carbon working electrode, $\mathrm{Pt}$ counter electrode, and $\mathrm{SE}$ re ence ele $\zeta \mathrm{de}$ at $\left(0.05,0.10,0.30,0.50 \mathrm{~V} . \mathrm{s}^{-1}\right)$.

Table 1. Elect hemical pa etors obtained from voltammograms of figure 2

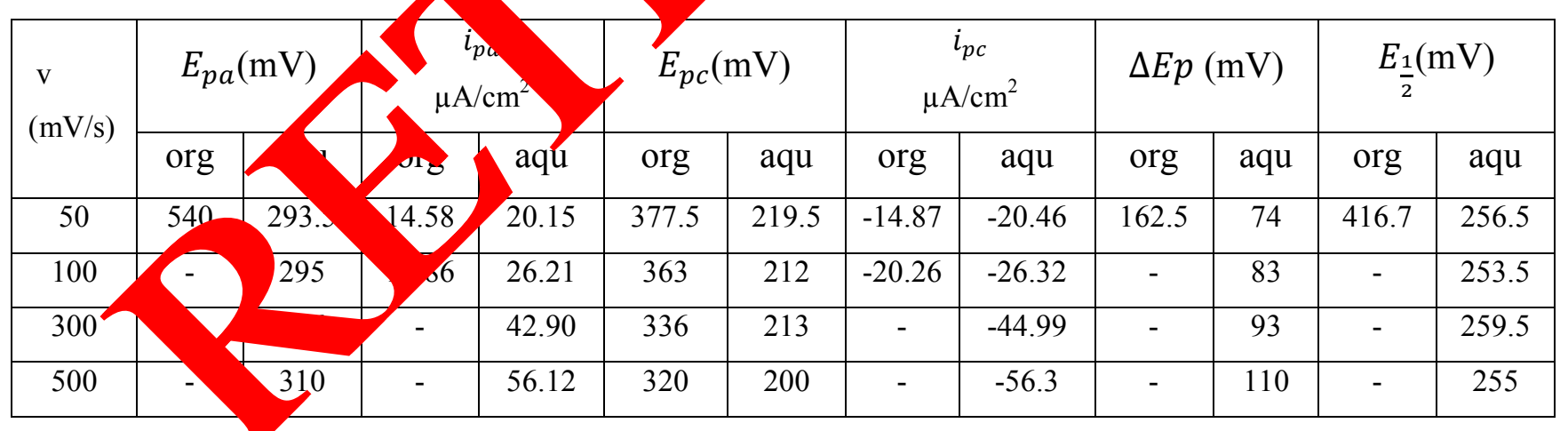

The peak potential spacing $(\Delta \mathrm{Ep})$, at scan rate equal to $0.05 \mathrm{~V} . \mathrm{s}^{-1}$ is $0.123 \mathrm{~V}$ for the ferrocene in $\mathrm{CH}_{2} \mathrm{Cl}_{2}$ and $0.064 \mathrm{~V}$ for the ferrocene in ethanol/water. A fast, reversible, oneelectron transfer would ideally have a $\Delta \mathrm{Ep}=0.059 \mathrm{~V}$ at $298 \mathrm{~K}$ [8]. The discrepancy from this ideal value is attributed to slow electron transfers and solution resistance.

The anodic and the cathodic peak heights as function of the square root of the scanning rate for platinum and glassy carbon electrodes electrode are shown in figure 3 . The obtained 
linear relationship indicates clear diffusion character. As it can be seen from figures 3 , the ratio of the anodic and cathodic current peak heights is close to one for both solutions; this indicates the reversible character of the oxidation of ferrocene in both studied medium.
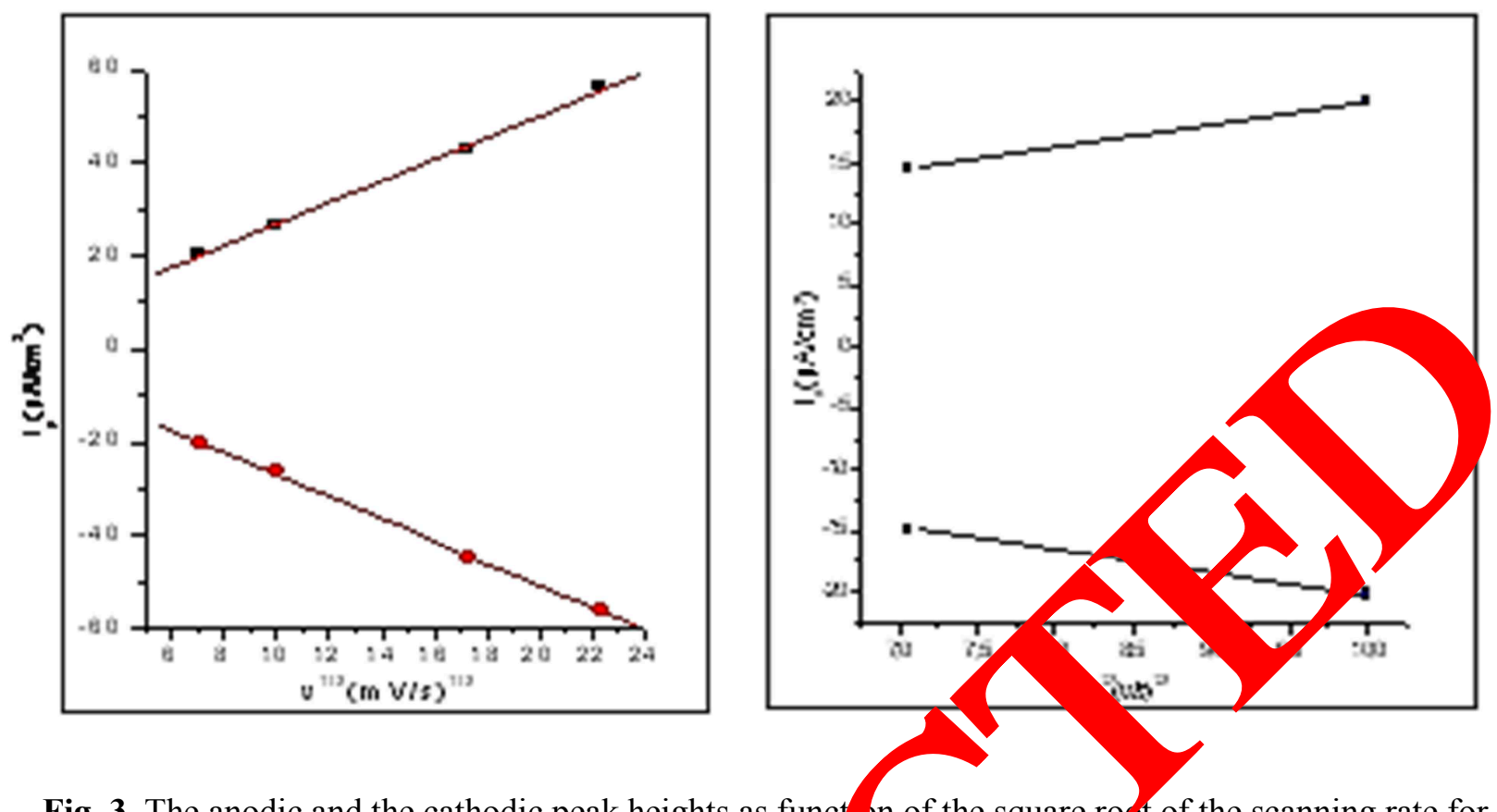

Fig. 3. The anodic and the cathodic peak heights as funct $n$ of the square root of the scanning rate for platinum electrode in $\mathrm{CH}_{2} \mathrm{Cl}_{2}$ (bleu) and in ethanol/1 $\quad \mathrm{SO}_{4}$ (red) at $1 \mathrm{~mm}$ diameter Pt working electrode.

\section{2. Diffusion of ferrocene and ferriceniun}

In general, the peak curr fiffu on controlled reversible or quasi-reversible electrochemical reaction folloy Rand $s$-Sevci -quation $[9,10]$ :

$$
=0.44) h F \sqrt{\frac{n F D}{R T}} A C \sqrt{v}
$$

where $\mathrm{i}_{\mathrm{p}}$ : the $\mathrm{p}$ ak current, $n$ : th aumber of electrons, $F$ : Faraday constant, $T$ : the temperature in Kelvin, $P$ e ga $a n s$ ant, $A$ : the surface area of the working electrode, $D$ : the diffusion coefficient of $\mathrm{L}$ ectroas ve species, $C$ : the bulk concentration of the electroactive species and $\mathrm{v}$ can $\mathrm{r}$ of oltammograms. Thus, the diffusion coefficients for ferrocene and fer eniun at $298 \mathrm{~K}$ e calculated from the slope of the plot of ip versus $\sqrt{v}$.

\section{3. E rochemical measurement on rotating disk electrode}

Thy diffusion coefficients of ferrocene organic and aqueous medium were also measured on a rotating disk electrode using the same conditions as used for voltammetry cyclic. The calculations were based on the Randles-Sevcik equation. That means the anodic peak height of ferrocene oxidation (obtained from voltammetry cyclic measurements) was measured in quiescent solutions on both electrodes and in both medium. The obtained polarogramme are showed in figure 4. 


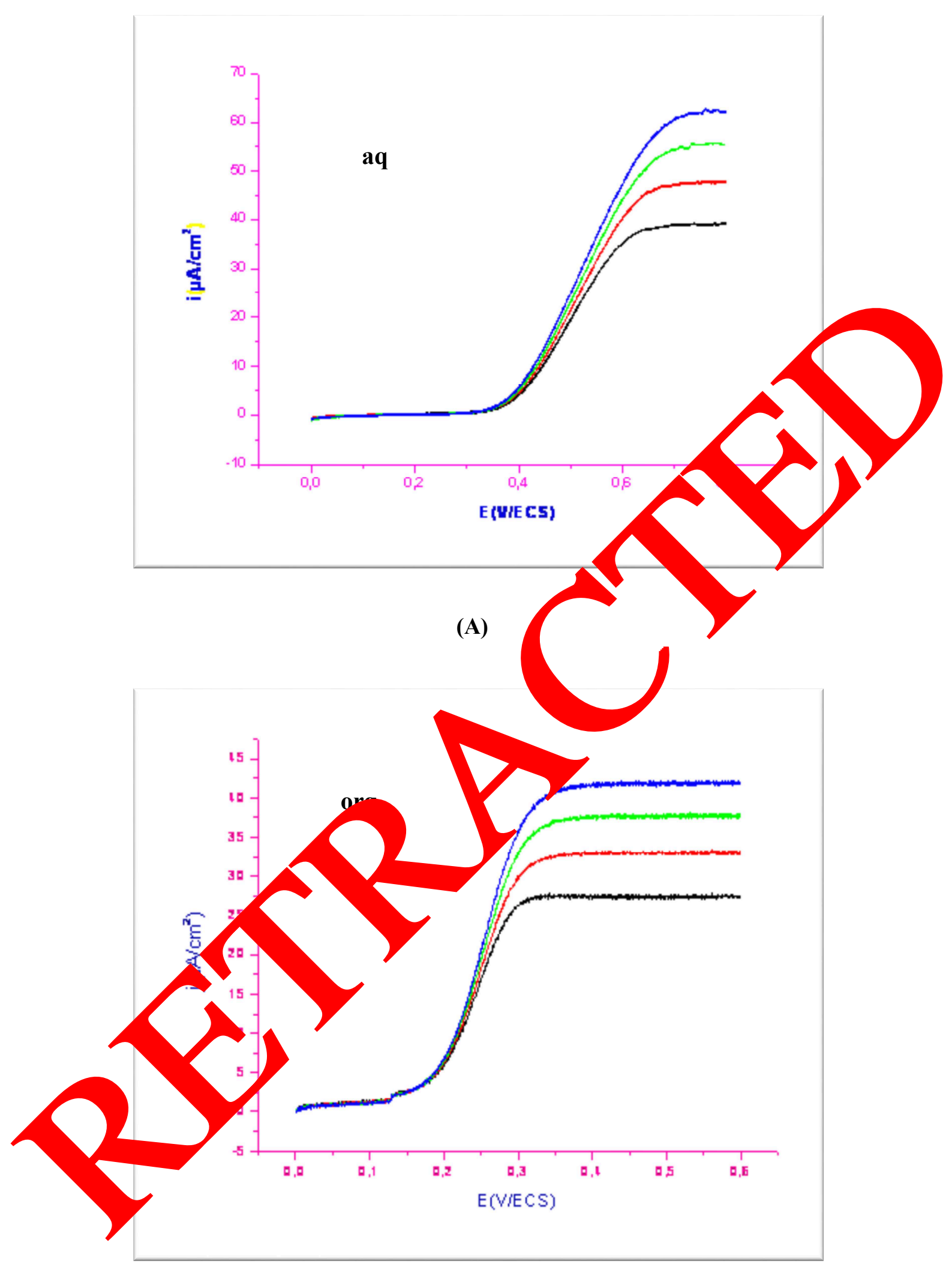

(B)

Fig. 4 (A, B). Polarogramme of ferrocene $1 \mathrm{mM}$ and $100 \mathrm{mM} \mathrm{Bu}_{4} \mathrm{NBF}_{4}$ in $\mathrm{CH}_{2} \mathrm{Cl}_{2}$ (left) and $1 \mathrm{mM}$ of ferrocene in ethanol $/ \mathrm{H}_{2} \mathrm{SO}_{4}$ (right) at $2 \mathrm{~mm}$ diameter glassy carbon working electrode, $\mathrm{Pt}$ counter electrode, and CSE reference electrode at $0.50{\mathrm{~V} . \mathrm{s}^{-1}}^{-}$. (Rotating rate 400, 600, 800, $1000 \mathrm{rpm}$ ) 
The anodic peak heights as function of the square root of the rotating disk electrode rate for platinum and glassy carbon electrodes are shown in figure 5. The coefficient diffusion for ferrocene is calculated from figure 5 as follows:
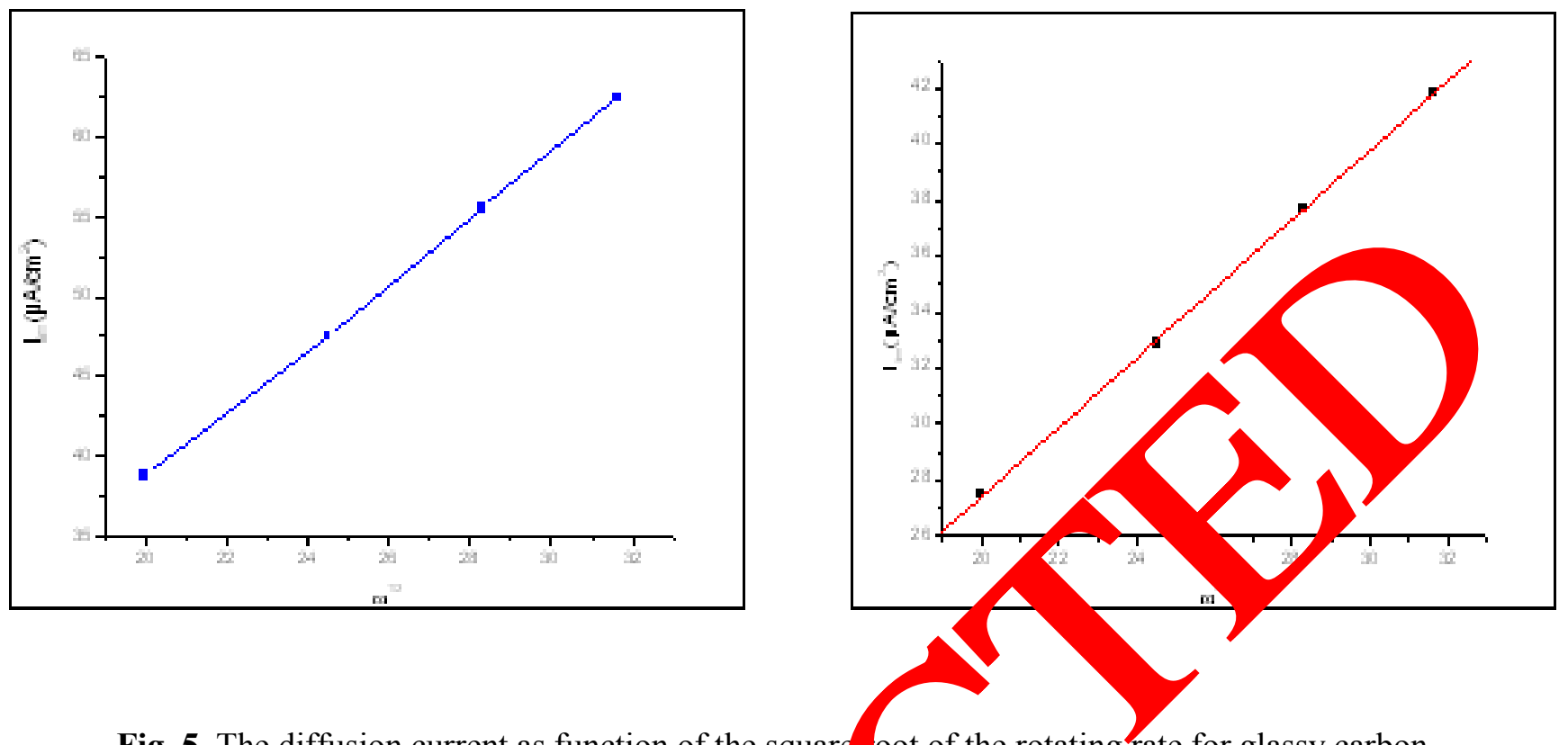

Fig. 5. The diffusion current as function of the square oot of the rotating rate for glassy carbon electrode in $\mathrm{CH}_{2} \mathrm{Cl}_{2}$ (bleu) and in hanol/ $\mathrm{H}_{2} \mathrm{SO}$ (red).

The Levich equation predicts the cur ered at ating disk electrode and shows that the current is proportional to the se rare rotation speed. The equation is:

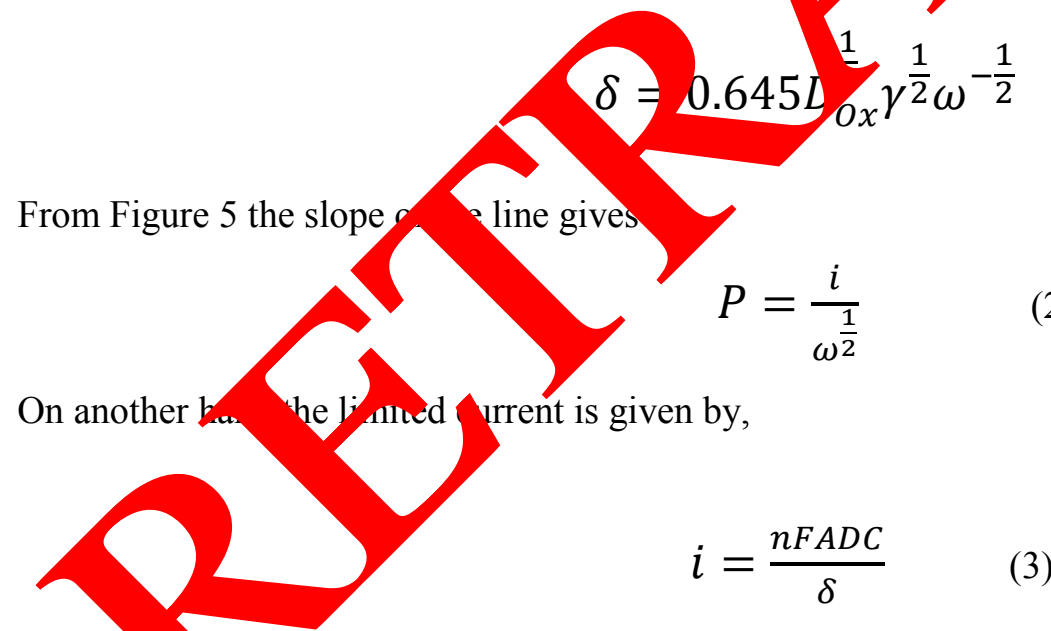

Where à number of electrons

$\mathrm{F}$ : is f Faraday $\left(9.65 .10^{4} \mathrm{C} / \mathrm{mol}\right)$

A: is the area of the working electrode $\left(\mathrm{cm}^{2}\right)$.

D: is the coefficient diffusion $\left(\mathrm{cm}^{2} \cdot \mathrm{s}^{-1}\right)$

$\mathrm{C}$ : is the concentration $\left(\mathrm{mol} / \mathrm{cm}^{3}\right)$, in our case is equal to $10^{-3} \mathrm{~mol} / 1$.

Replacing equations 2 and 3 in 4 gives,

$$
D^{\frac{2}{3}}=\frac{P 1.61 \gamma^{\frac{1}{6}}}{n F A C \sqrt{2 \pi}}
$$


For a rotating rate of the working electrode equal to $400 \mathrm{t} / \mathrm{min}$., the coefficient diffusion of ferrocene in dichlormethane is.

$$
D=77.16 \times 10^{-6} \mathrm{~cm}^{2} \cdot \mathrm{s}^{-1}
$$

The coefficient diffusion of ferrocene in aqueous ethanol is calculated as above. Table 2 summarize the obtained values.

Table 2. Diffusion coefficients of ferrocene calculated from polarogramme of figure 5.

\begin{tabular}{|c|c|c|c|}
\hline Electrode/medium & $p$ & $D \times 10^{-6} \mathrm{~cm}^{2} / \mathrm{s}$ & $\delta(\mathrm{nm})$ \\
\hline $\mathrm{GC} / \mathrm{CH}_{2} \mathrm{Cl}_{2}$ & 1.95 & 77,16 & \\
\hline GC /aq.ethanol & 1.34 & 32,82 & \\
\hline
\end{tabular}

Voltammetry analysis on a fixed and on a rotatir ectroc ferrocene in aqueous and organic solutions indicates that the electrochemig a reaction of to cene in both studied solutions is a diffusion controlled process, nam ly, single electron transfer reversible electrochemical process. The diffusion coefficien of ferricen um and ferrocene in both organic and aqueous solutions are almost in the order of magnitude. This is most probably because the size of the solvated f cenium an wocene is much smaller than the size of the pores of three-dimensional netwo is.

\section{ACKNOWLEDGMENTS}

Support of the work by the $\mathrm{bo}$, iv sation et promotion des resources sahariennes is gratefully acknowledg 1 . We wo vike to thank Professor M. SAIDI, for his help.

\section{REFEREN \\ [1] P. Molina, Tarrage, D. Curiel, M. D. Vel, Journal of Organometallic Chemistry 258}

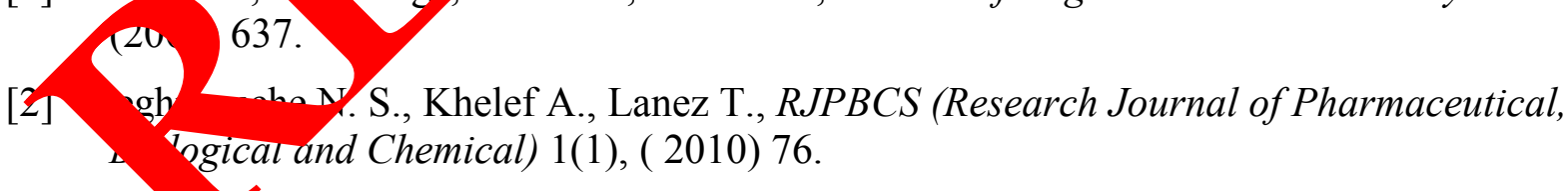

[3] Negh, uche N. S., Khelef A., Lanez T., Rev. Sci. Fond. App. 1(1) (2009) 23-30.

[4] Bard A. J., Faulkner L. R., Electrochemical Methods: Fundamentals and Applications, New York: John Wiley \& Sons, 1980.

[5] Cleary J., Bromberg L. E., Magner E., Langmuir 19 (2003) 9162.

[6] Morikita T., Yamamoto T., J. Organomet. Chem. 809 (2001) 637-639.

[7] Mahajan R. K., Kaur N., Bakshi M. S., Physicochem. Eng. Aspects 276 (2006) 221. 
[8] Eisele S., Schwarz M., Speiser B., Tittel C., Electrochim. Acta 51 (2006) 5304.

[9] Matsumoto H., Yanagida M., Tanimoto K., Nomura M., Kitagawa Y., Miyazaki Y., Chem. Lett. 29 (2000) 922.

[10] Molina P., Ta'rraga A., Curiel D., Vel M. D., Journal of Organometallic Chemistry 258 (2001) 637.

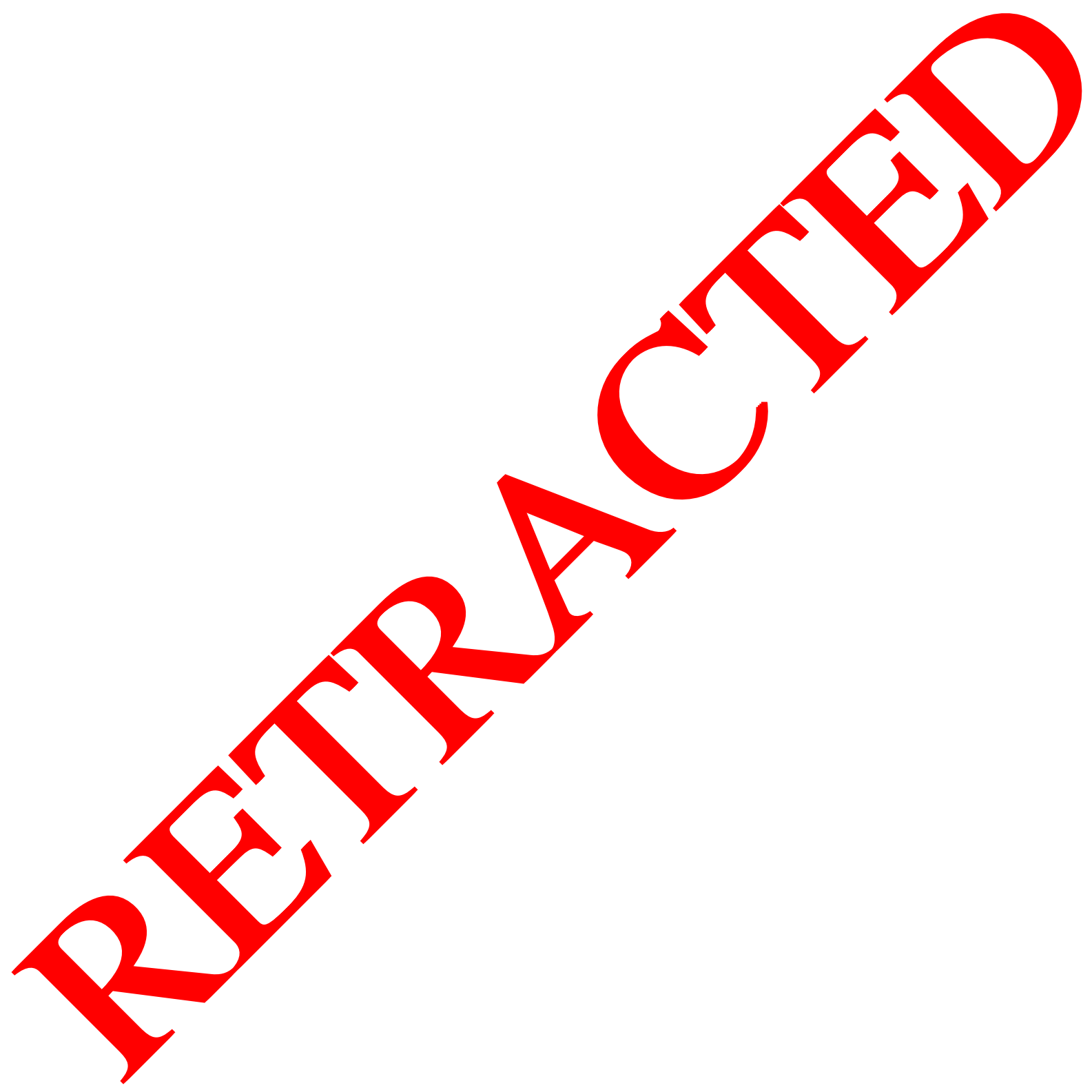

